\title{
Familial neurofibromatosis type 1 associated with an overgrowth syndrome resembling Weaver syndrome
}

\author{
C J van Asperen, W C G Overweg-Plandsoen, M H Cnossen, D A van Tijn, \\ R C M Hennekam
}

\begin{abstract}
The simultaneous occurrence of familial neurofibromatosis type 1 (NF1) and an overgrowth syndrome resembling Weaver syndrome was observed in two related cases (a mother and her son). NF1 was confirmed by molecular genetic analysis showing a large deletion at 17q11.2, encompassing the entire NF1 gene. The other symptoms in the two cases were similar to the features reported in Weaver syndrome.

Although the combination of NF1 and an overgrowth syndrome resembling Weaver syndrome in this family may be fortuitous, we favour the hypothesis that the deletion of the entire gene has caused this combined phenotype. Possible pathogenetic mechanisms are discussed. The observation suggests a relation between NF1 with an extraordinarily large gene deletion and a Weaver(-like) syndrome. This warrants investigation for deletions in the $17 q 11.2$ region in Weaver(-like) syndrome patients.

(F Med Genet 1998;35:323-327)
\end{abstract}

Key words: neurofibromatosis type 1; entire gene deletion; overgrowth; Weaver syndrome

Neurofibromatosis type 1 (NF1) is a common, autosomal dominantly inherited disorder characterised by café au lait spots, Lisch nodules, and neurofibromas. The NF1 gene has been cloned and maps to chromosome 17q11.2 and is probably a tumour suppressor gene. The protein was named neurofibromin. ${ }^{12}$ In $40-$ $50 \%$ of cases, NF1 results from a spontaneous mutation.

There are more than 10 clinical syndromes that should be considered in the clinical evaluation of NF1, and numerous other disorders that share at least some features with NF1. For the most part, these conditions are fairly distinct and the differences from NF are relatively obvious. ${ }^{3}$

Some patients with classical NF1 have, in addition, features of dysmorphic syndromes, such as Noonan syndrome or Watson syndrome. $^{4-8}$ The overlapping features of Watson syndrome, Noonan syndrome, and NF1 may imply a series of contiguous genes for NF1, vessel anomalies including pulmonary stenosis, and lymphatic abnormalities, and perhaps short stature and macrocephaly. ${ }^{9}$ This was supported by the finding of NF1 mutations in a Watson syndrome patient ${ }^{10}$ and in a family with features fitting Watson and Noonan syndromes. ${ }^{11}$ However, no linkage to the NF1 or NF2 loci has been found in families with only Noonan syndrome. ${ }^{12}{ }^{13}$ In NF1 patients with mild dysmorphic features, variable mental retardation, exceptionally large numbers of neurofibromas, and very large de novo deletions $(>700 \mathrm{~kb})$ including the entire NF1 gene have been described. ${ }^{14-16}$ In a recent series of 84 Dutch patients, five complete deletions were found, including three sporadic patients with features confirming the earlier reports. ${ }^{17}$ Two other related patients, however, showed a different picture, including overgrowth.

The association of NF1 with an overgrowth syndrome has not been previously reported. In this report we present these latter patients in detail. Detailed molecular genetic data are reported elsewhere. ${ }^{17}$

\section{Case reports}

Case 1 was the first born child of nonconsanguineous parents. Paternal and maternal ages at his birth were 32 and 30 years, respectively. Weight at birth was $3830 \mathrm{~g}$ (95th centile) and length was $52 \mathrm{~cm}$ (between the 50th and 95th centile). His motor development has always been normal (walking at 15 months) but his parents described him as clumsy. Talking started at 20 months of age. At that age he was referred to the Neurofibromatosis Working Group because the infant welfare centre suspected him to have NF.

Anthropometrics showed height, weight, and head circumference to be at or above the 90 th centile (fig 1A, B). He had six café au lait spots of over $5 \mathrm{~mm}$ in diameter and no Lisch nodules or neurofibromas. Furthermore, he had a remarkable, coarse face (fig $2 \mathrm{~A}, \mathrm{~B}$ ) including a broad forehead, hypertelorism, epicanthic folds, prominent philtrum, large ears, and slight micrognathia. Further physical examination showed prominent finger pads and hyperextensible fingers. An $x$ ray of the left wrist showed the osseous maturation to be one year advanced.

At 2 years 2 months of age he developed visual disturbances, which appeared to be caused by a glioma involving both optic nerves and the chiasm. A policy of careful ophthalmological and MRI follow up was adopted and no changes were apparent in the following years. Extensive endocrine studies were undertaken because of the continuing overgrowth. Hormo-

nal studies showed a normal curve for growth
Received 19 June 1997 Revised version accepted for publication 26 September 1997 

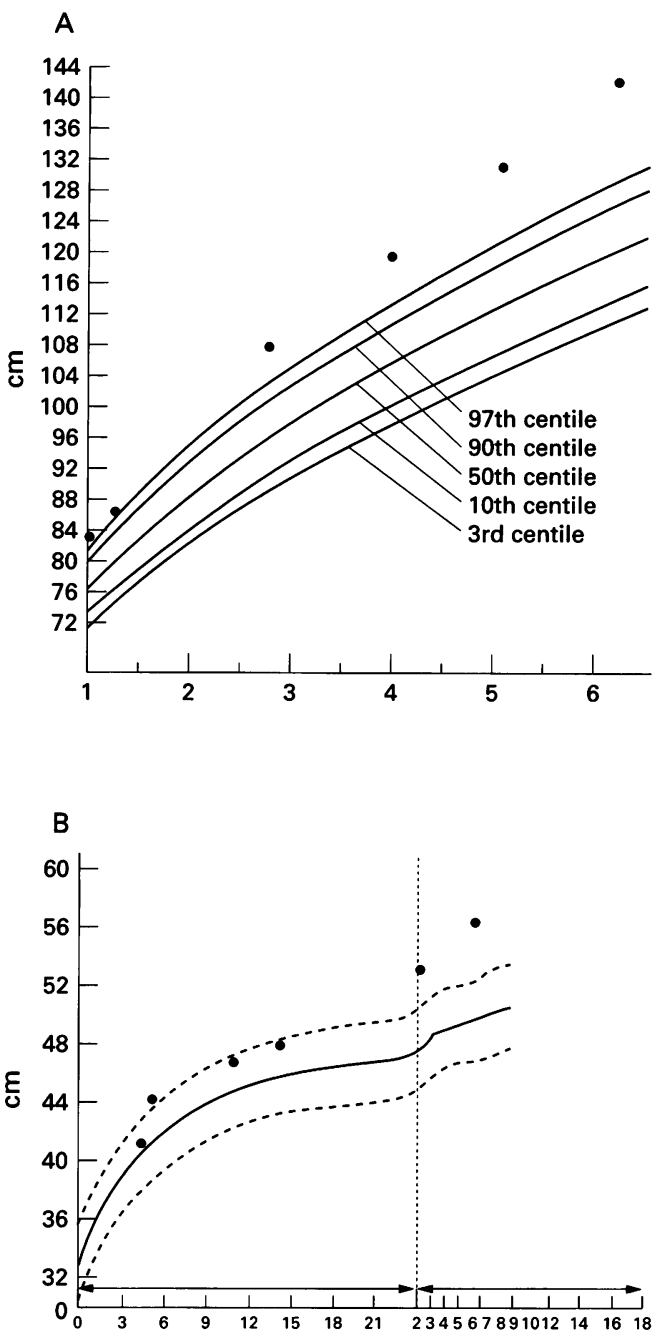

Figure 1 (A) Growth curve for height of case 1. (B) Head circumference curve of case 1 . In retrospect overgrowth seems to have started after the first 6 months of life.

hormone although there was an increased reaction of prolactin after the fasting TRH test. The levels of all other investigated hormones, T3, free T4, TSH, somatomedin, prolactin, IGF 1, IGF 2, IGFBP-3, LH, FSH, and testosterone, were normal. He had a normal male karyotype $(46, \mathrm{XY})$; molecular studies showed no signs of fragile $\mathrm{X}$ syndrome.
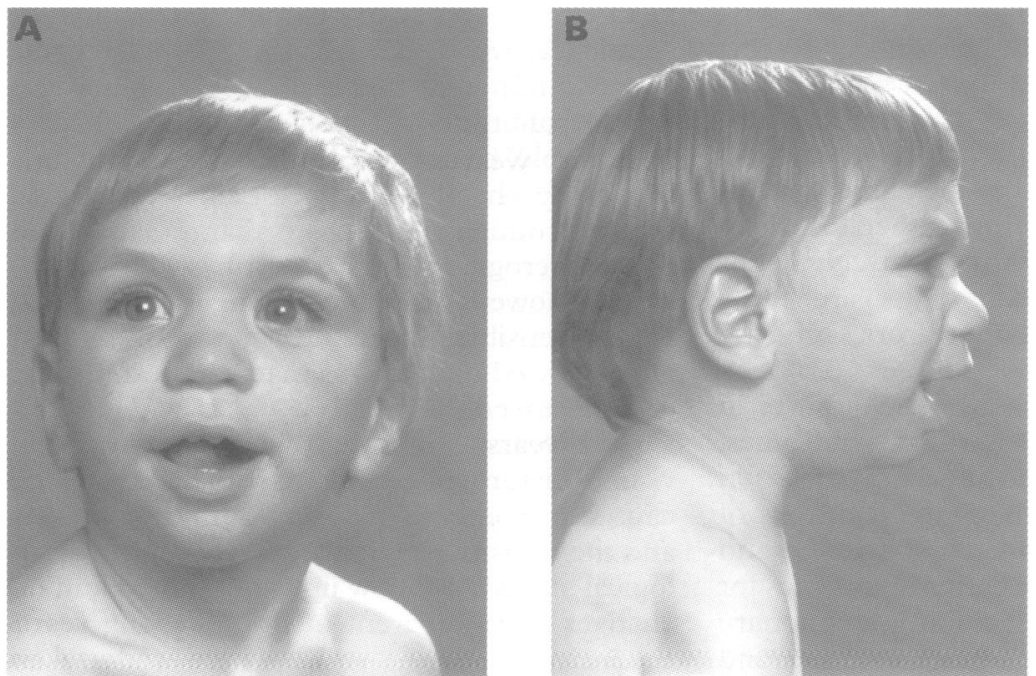

Figure $2(A, B)$ Remarkable coarse face of case 1 at the age of 2 years. (All photographs reproduced with permission.)

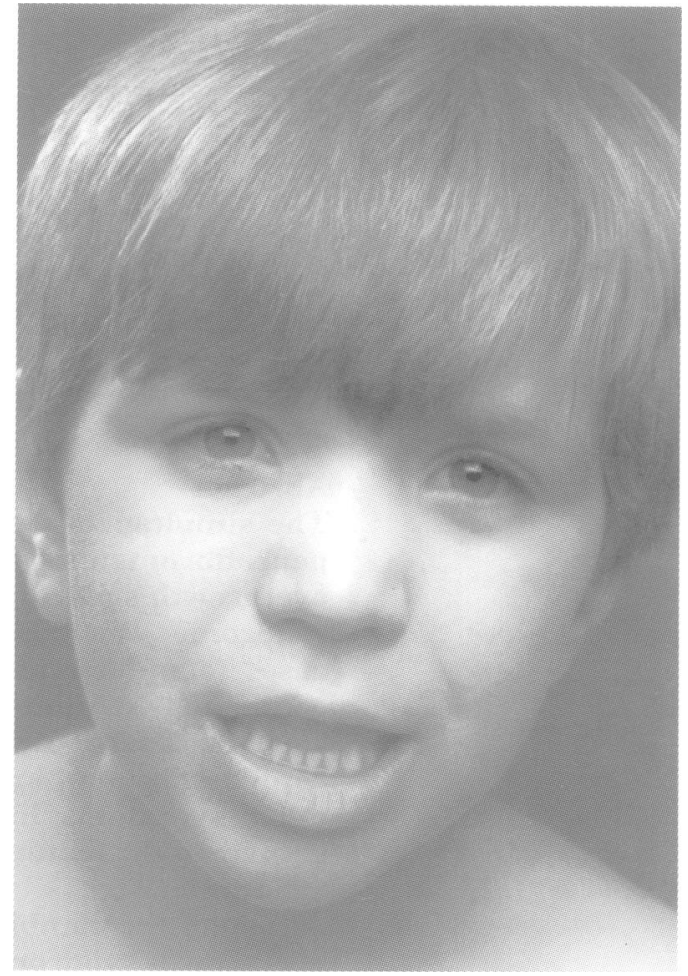

Figure $3 \quad$ Face of case 1 at the age of 5 years.

In subsequent years moderate psychomotor retardation and behavioural problems became apparent. There was a further growth acceleration and the skeletal age became even more advanced (at the age of 4 years his bone age was 7 years). He developed axillary freckling and neurofibromas on the upper limbs. No Lisch nodules have been detected as yet. His face has become longer and less distinctive (fig 3 ).

Case 2 was the mother of case 1. A diagnosis of NF1 was made by a dermatologist at 31 years of age based on multiple café au lait spots and numerous neurofibromas. Remarkably, in early reports by her general practitioner, she was described as a girl with "gargoylism" (M Hurler). A conspicuously coarse face and tall stature were also evident on young photographs (fig 4A, B). She had an operation for an umbilical hernia at 1 year of age. At the age of $4 \frac{1}{2}$ years she was said to have had a normal skeletal age. Unfortunately these $x$ rays were no longer available. Menarche took place at the age of 14 years. No further details have been available about her growth curve. She has had mild learning problems. At the time of investigation she had a normal height of $1.76 \mathrm{~m}$ (90th centile), a weight of $74 \mathrm{~kg}$ (90th centile), and a head circumference of $59.5 \mathrm{~cm}$ (98th centile). Her NF1 features consisted of café au lait spots, more than 200 neurofibromas, Lisch nodules, and freckling (fig 5). An MRI showed no cranial abnormalities and no optic pathway glioma. Numerous subcutaneous neurofibromas were also seen around the carotid artery sheath. By history, there were no other family members affected with NF1. Unfortunately the parents of case 2 were not available for further investigations. 

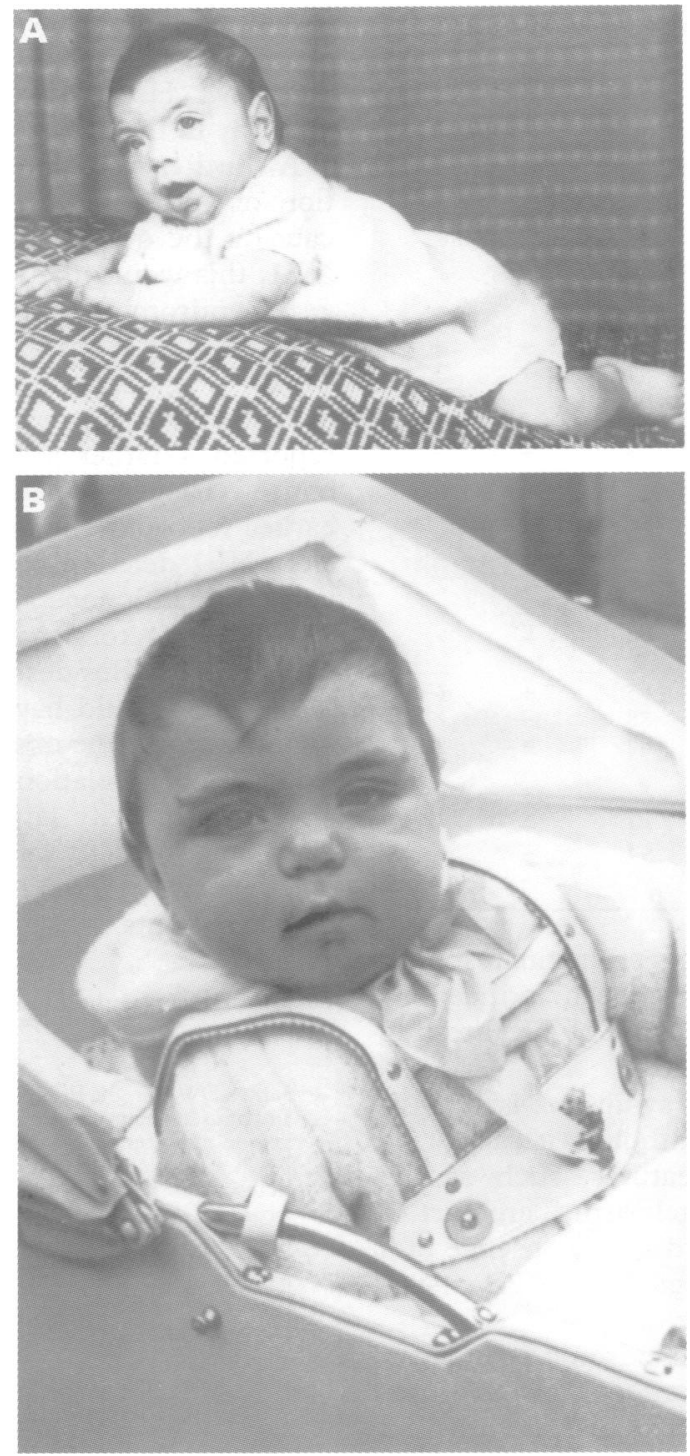

Figure 4 (A, B) Photographs of case 2 at a young age (exact age not known).

\section{MOLECULAR GENETIC STUDIES}

Molecular genetic studies were performed in both cases with intragenic polymorphic markers and Southern analysis, as described in detail elsewhere. ${ }^{15}$ Both cases had a large deletion of approximately $700 \mathrm{~kb}$, including the whole NF1 gene between marker D17S117 (VAW212R2i) and CDNA probe GE2 situated on the centromeric side of the NF1 gene, and between D17S115 (VAW210M1) and CDNA probe B3A situated on the telomeric side of the NF1 gene.

\section{Discussion}

The diagnosis of NF1 is obvious as the international diagnostic criteria are fulfilled in both cases. ${ }^{18}$ Case 1 had more than six café au lait spots, freckling, optic pathway glioma, and several neurofibromas; case 2 had café au lait spots, Lisch nodules, freckling, and numerous neurofibromas. In both cases the diagnosis of NF1 was confirmed by the molecular genetic results showing a large deletion at $17 q 11.2$, encompassing the entire NF1 gene.

Case 1 shows many features of an overgrowth syndrome and some of these features are also present in case 2. Although the boy in our report had an optic pathway glioma involv-

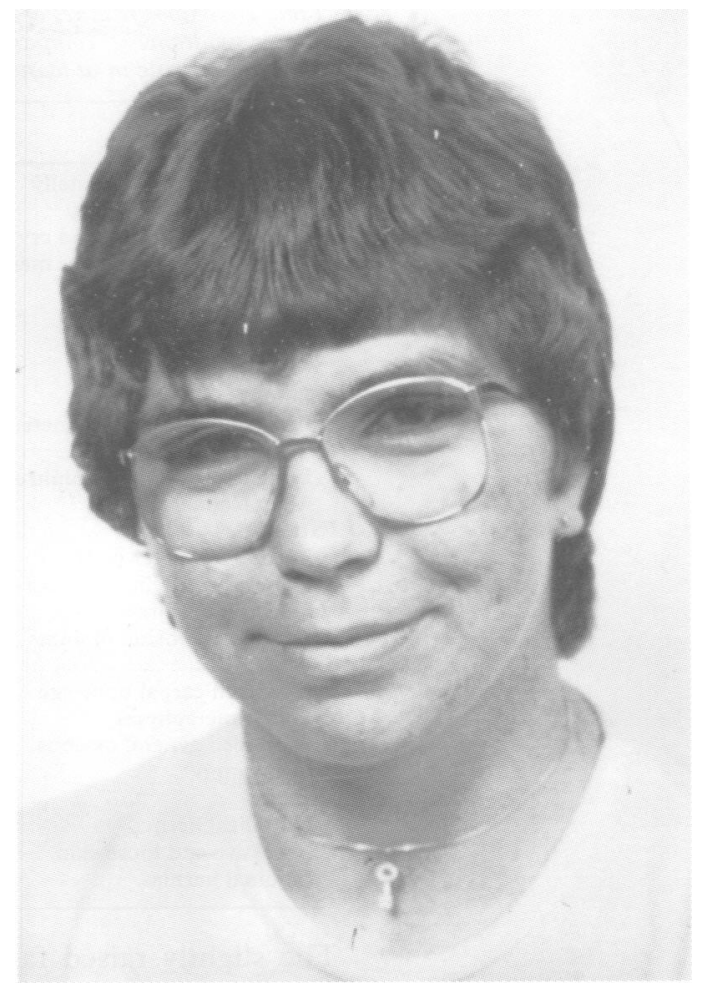

Figure 5 Face of case 2 as an adult.

ing the chiasm, which could cause hormonal disturbances of hypophyseal functions, we have been unable to find any evidence for such a relationship.

In general, classification of overgrowth syndromes is difficult because of the lack of hard diagnostic criteria. ${ }^{19} 20$ In a recent review of Sotos syndrome and Weaver syndrome, it was stated that the main method to establish a diagnosis is evaluation (of photographs) of the "facial gestalt" between 1 and 6 years of age. ${ }^{21} 22$

In the present family, the face of case 1 shows a strong resemblance to the craniofacial features reported in Weaver syndrome, and a photograph from childhood of case 2 shows this as well: ocular hypertelorism, epicanthic folds, large ears, long philtrum, and slight micrognathia. Other features often reported in patients with Weaver syndrome and present in this family were developmental delay, prominent fingerpads, and an umbilical hernia (in case 2). Case 1 had no widening of the metaphyses. Although this is reported in most cases of Weaver syndrome, it is not an obligatory feature. ${ }^{21}{ }^{23} \mathrm{~A}$ comparison of the present cases with the major features in Weaver syndrome is shown in table $1 .^{2024}$

Other overgrowth syndromes such as Simpson-Golabi-Behmel syndrome and Perlman syndrome can be reliably ruled out, particularly by their differing facial phenotypes and the absence of internal abnormalities in the present patients. $^{21} 25$

Endocrinological investigations have been normal in most cases with Weaver syndrome. Acquired hypothyroidism, however, has been reported in one case, ${ }^{26}$ and in a familial case of Weaver syndrome the son had a low basal and stimulated human growth hormone level and the affected mother had hyperprolactinaemia. ${ }^{27}$ 
Table 1 Major features of 39 published patients with Weaver syndrome ${ }^{1923}$ compared with present cases. Only features occurring in at least $75 \%$ of cases are included

\begin{tabular}{|c|c|c|c|}
\hline & Percentage & Case 1 & Case 2 \\
\hline Excessive growth postnatally & 92 & + & + \\
\hline Performance motor delay & 95 & + & $?$ \\
\hline Hoarse and low pitched cry & 90 & - & $?$ \\
\hline retardation & 80 & + & \pm \\
\hline \multicolumn{4}{|l|}{ Craniofacial } \\
\hline Micrognathia & 97 & + & + \\
\hline Ocular hypertelorism & 97 & + & + \\
\hline Large ears & 96 & + & + \\
\hline Increased bifrontal diameter & 96 & + & + \\
\hline Telecanthus & 96 & - & - \\
\hline Long and prominent philtrum & 82 & + & + \\
\hline Macrocephaly & 79 & + & + \\
\hline \multicolumn{4}{|l|}{ Extremities } \\
\hline Prominent finger pads & 93 & + & ? \\
\hline Hyperextensibility of fingers & 80 & + & ? \\
\hline Deep set or narrow nails & 77 & - & ? \\
\hline Limited extension of joints & 79 & - & ? \\
\hline \multicolumn{4}{|l|}{ Skeleton } \\
\hline Increased carpal bone age & 95 & + & $(-)$ \\
\hline Flared metaphyses & 88 & - & $?$ \\
\hline $\begin{array}{l}\text { Advanced general osseous } \\
\text { maturation }\end{array}$ & 82 & + & ? \\
\hline \multicolumn{4}{|l|}{ Others } \\
\hline Umbilical hernia & 84 & - & + \\
\hline Excessive and loose skin & 94 & - & $?$ \\
\hline Inguinal hernias & 90 & - & - \\
\hline
\end{tabular}

The slightly raised fasting prolactin response found in case 1 may have been induced by stress, but may also be because of TRH testing or hypothalamic dysfunction.

In our opinion, Weaver syndrome is a possible diagnosis in case 1 , although it cannot be excluded that several features, such as the macrocephaly and hypertelorism, ${ }^{28}$ are part of the spectrum of NF1, and in the absence of a diagnostic marker the diagnosis of Weaver syndrome remains a tentative one.

The cause of Weaver syndrome is unclear. Males are reported to be affected twice as frequently as females. Affected males with mild expression of the syndrome in their mothers have been described repeatedly. ${ }^{232729} 30$ This is most compatible with autosomal dominant inheritance with sex limited expression or X linked recessive inheritance. Male to male transmission has not been reported so far. However, most cases have been sporadic.

Autosomal recessive inheritance has also been suggested, ${ }^{31-33}$ but the patients reported by Teebi $e t a l^{3}$ almost certainly do not have Weaver syndrome, ${ }^{21}$ the patient reported by Roussounis and Crawford ${ }^{31}$ has been shown to have a chromosome anomaly (46,XX,5p-), and the data in the paper by Jalaquier et $a l^{22}$ are insufficient to allow a conclusion of autosomal recessive inheritance.

The combination of NF1 with Weaver-like syndrome in two related patients may be a chance finding without a causal relationship. Another, admittedly speculative, explanation may be that the deletion at $17 \mathrm{q} 11.2$ has influenced the functional activity of an unknown growth factor. In this respect it should be noted that a de novo nonsense mutation in the NF1 gene was found in a patient with another entity showing overgrowth features, that is, encephalocraniocutaneous lipomatosis. ${ }^{34}$ Furthermore, other overgrowth syndromes, such as Simpson-Golabi-Behmel syndrome and Beckwith-Wiedeman syndrome involving different genes on Xq26 and $11 \mathrm{p} 15$ respectively, both followed the same (IGF2) pathway. ${ }^{35}$ Hence further studies of the IGF2 pathway in the present patients may be useful.

A third explanation is the potential disruption of another gene close to the NF1 gene causing the overgrowth. In combination with NF1, this would then constitute a contiguous gene syndrome. It remains difficult to explain why other reported patients with a deletion of similar magnitude have not shown symptoms of an overgrowth syndrome, although Wu et a ${ }^{36}$ reported a father and son both carrying an entire NF1 gene deletion who had, apart from earlier reported clinical characteristics of this large NF1 deletion, large hands and feet. The epigenetic influence(s) of modifying genes ${ }^{37}$ or exogenous factors may be important to both explanations. Besides this, the genomic rearrangements could have caused position effect phenomena. ${ }^{38}$ The observations do suggest the existence of a relationship between NF1 with an extraordinarily large deletion and Weaver syndrome, which warrants investigation for deletions in the $17 \mathrm{q} 11.2$ region in Weaver syndrome patients.

The cooperation of the present family is gratefully acknowledged.

1 Barker DW, Wright E, Nguyen K, et al. Gene for von Recklinghausen neurofibromatosis is in the pericentromeric region of chromosome 17 . Science 1987;236:1100-2.

2 DeClue JE, Cohen BD, Lowy DR. Identification and characterization of the neurofibromatosis type 1 protein product. Proc Natl Acad Sci USA 1991;88:9914-18.

3 Huson SM, Hughes RAC. The neurofibromatoses. A pathoge netic and clinical overview. London, Chapman and Hall,

4 Mendez HMM. The neurofibromatosis-Noonan syndrome Am $\mathcal{F}$ Med Genet 1985;21:471-6.

5 Allanson JE, Hall JG, Van Allen MI. Noonan phenotype associated with neurofibromatosis. Am $\mathcal{F}$ Med Genet 1985;21:457-62

6 Kaplan P, Rosenblatt B. A distinctive facial appearance in neurofibromatosis von Recklinghausen. $\mathrm{Am} \mathcal{7}$ Med Genet 1985;21:463-70

7 Colley A, Donnai D, Evans DGR. Neurofibromatosis/ Noonan phenotype: a variable feature of type 1 neurofibromatosis. Clin Genet 1996;49:59-64.

8 Watson GH. Pulmonary stenosis, cafe-au-lait spots, and dull intelligence. Arch Dis Child 1967;42:303-7.

9 Allanson JE, Upadhyaya M, Watson GH, et al. Watson syndrome: is it a subtype of type 1 neurofibromatosis? $\mathcal{f}$ syndrome: is it a subtype

10 Upadhyaya M, Maynard J, Osborn M, et al. Characterisation of germline mutations in the neurofibromatosis type 1 (NF1) gene. F Med Genet 1995;32:706-10.

11 Tassbehji M, Strachan T, Sharland M, et al. Tandem duplication within a neurofibromatosis type 1 (NF1) gene exon in a family with features of Watson syndrome and Noonan syndrome. Am $\mathcal{F}$ Hum Genet 1993;53:90-5.

12 Sharland M, Taylor R, Patton MA, Jeffery S. Absence of linkage of Noonan syndrome to the neurofibromatosis type 1 locus. F Med Genet 1992;29:188-90.

13 Flintoff WF, Bahuau M, Lyonnet S, et al. No evidence for linkage to the type 1 or type 2 neurofibromatosis loci in Noonan syndrome families. Am f Med Genet 1993;46:7005.

14 Kayes LM, Burke W, Riccardi VM, et al. Deletions spanning the neurofibromatosis 1 gene: identification and phenotype of five patients. Am $\mathcal{F}$ Hum Genet 1994;54:424-36.

15 Wu BL, Austin MA, Schneider GH, Boles RG, Korf BR. Deletions of the entire NF1 gene detected by FISH: four deletion patients associated with severe manifestations. $\mathrm{Am}$ deletion patients associated with

16 Leppig KA, Viskochil D, Neil S, et al. The detection of contiguous gene deletions at the neurofibromatosis 1 locus with fluorescence in situ hybridization. Cytogenet Cell Genet 1996;72:95-8

17 Cnossen $\mathrm{MH}$, van der Est $\mathrm{MN}$, Breuning $\mathrm{MH}$, et al. Deletions spanning the neurofibromatosis type 1 gene (NF1): implications for genotype-phenotype correlation in neurofibromatosis type 1? Hum Mutat 1997;9:458-64.

18 National Institute of Health Consensus Development Conference. Neurofibromatosis Conference Statement. Arch Neurol 1988;45:575-8.

19 Cohen MM Jr. A comprehensive and critical assessment of overgrowth and overgrowth syndromes. Adv Hum Genet 1989;18:262-74 
20 Scarono G, Della Monica M, Lonardo F, Neri G. Novel findings in a patient with Weaver or a Weaver like findings in a patient with Weaver or a 21 Cole TRP, Dennis NR, Hughes HE. Weaver syndrome. $f$

22 Cole TRP, Hughes HE. Sotos syndrome: a study of the diagnostic criteria and natural history. $f$ Med Genet 1994;31:20-32

23 Ardinger $\mathrm{HH}$, Hanson JW, Harrod MJE, et al. Further delineation of Weaver syndrome. F Pediatr 1986;108:228-35.

24 Proud VK, Howenstein D, Weaver DD. Weaver syndrome a single dominant gene causing overgrowth in a family: case report and review of literature. Dave $W$ Smith Workshop on Morphogenesis and Congenital Malformations, 1992:39.

25 Coppin B, Moore I, Hatchwell E. Extending the overlap of three congenital overgrowth syndromes. Clin Genet 1997; 51:375-8.

26 Amir N, Gros-Kieselstein E, Hirsch HJ, et al. Weaver-Smith syndrome: a case study with long term follow up. $A m \mathcal{F} D$ i 183:1113-17.

27 Stoll C, Talon P, Mengus M, Roth P, Dott B. A Weaver-like syndrome with endocrinological abnormalities in a boy and a mother. Clin Genet 1985;28:255-9.

28 Westerhof W, Delleman JW, Wolters E, Dijkstra P. Neurofibromatosis and hypertelorism. Arch Dermatol 1984;120: 1579-81.

29 Majewski F, Ranke M, Kemperdick H, Schmidt E. The Weaver syndrome: a rare type of primordial overgrowth Eur F Pediatr 1981;137:277-82.
30 Dumic $M$, Vukovic J, Cvitkovic $M$, Medica I. Twins and their mildly affected mother with Weaver syndrome. Clin Genet 1993;44:338-40.

31 Roussounis SH, Crawford MJ. Siblings with Weaver syndrome. F Pediatr 1983;102:595-7.

32 Jalaquier J, Montaya F, Germain M, Bonnet H. Avance de la maturation osseuse et syndrome dysmorphique chez deux germains. F Genet Hum 1983;5:385-95.

33 Teebi AS, Sundareshan TS, Hammouri MY, et al. A new autosomal recessive disorder resembling Weaver syndrome. Am f Med Genet 1989;33:479-82.

34 Legius E, Wu R, Eyssen M, Marynen P, Frijns JP, Cassiman $\mathrm{JJ}$. Encephalocraniocutaneous lipomatosis with a mutation in the NF1 gene. 7 Med Genet 1995;32:316-19.

35 Lindsey S, Ireland M, O'Brien O, et al. Large scale deletions in the GPC3 gene may account for a minority of cases of Simpson-Golabi-Behmel syndrome. $\mathcal{F}$ Med Genet 1997;34: 480-3.

36 Wu BL, Schneider GH, Korf BR. Deletions of the entire NF1 gene causing distinct manifestations in a family. $A m \mathcal{F}$ Med Genet 1997;69:98-101.

37 Easton DF, Ponder MA, Huson SM, Ponder BAJ, An analysis of variation in expression of neurofibromatosis (NF) type 1 (NF1): evidence of modifying genes. Am $\mathcal{F}$ Hum Genet 1993;53:305-13.

38 Milot E, Fraser P, Grosveld F. Position effects and genetic disease. Trends Genet 1996;12:123-6. 